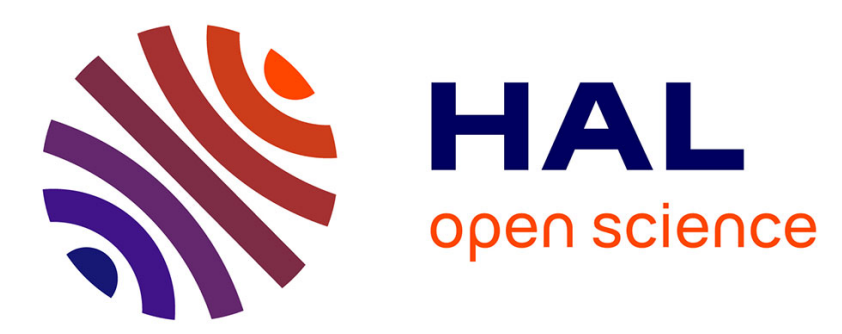

\title{
Automatic generation of personalised skeletal models of the lower limb from three-dimensional bone geometries
}

Luca Modenese, Jean-Baptiste Renault

\section{To cite this version:}

Luca Modenese, Jean-Baptiste Renault. Automatic generation of personalised skeletal models of the lower limb from three-dimensional bone geometries. Journal of Biomechanics, 2021, 116, pp.110186. 10.1016/j.jbiomech.2020.110186 . hal-03190776

\section{HAL Id: hal-03190776 https://hal.science/hal-03190776}

Submitted on 6 Apr 2021

HAL is a multi-disciplinary open access archive for the deposit and dissemination of scientific research documents, whether they are published or not. The documents may come from teaching and research institutions in France or abroad, or from public or private research centers.
L'archive ouverte pluridisciplinaire HAL, est destinée au dépôt et à la diffusion de documents scientifiques de niveau recherche, publiés ou non, émanant des établissements d'enseignement et de recherche français ou étrangers, des laboratoires publics ou privés. 


\title{
Automatic generation of personalised skeletal models of the lower limb from three-dimensional bone geometries
}

\author{
Luca Modenese $^{\mathrm{a}, *}$, Jean-Baptiste Renault ${ }^{\mathrm{b}}$ \\ ${ }^{a}$ Department of Civil and Environmental Engineering, Imperial College London, UK \\ ${ }^{\mathrm{b}}$ Aix-Marseille University, CNRS, ISM UMR 7287, 13009 Marseille, France
}

\section{A R T I C L E I N F O}

\section{Article history:}

Accepted 11 December 2020

\section{Keywords:}

Anatomical coordinate system

Lower limb

Skeletal model

Musculoskeletal model

Kinematics

Three-dimensional bone model

Surface fitting

3D imaging

\begin{abstract}
A B S T R A C T
The generation of personalised and patient-specific musculoskeletal models is currently a cumbersome and time-consuming task that normally requires several processing hours and trained operators. We believe that this aspect discourages the use of computational models even when appropriate data are available and personalised biomechanical analysis would be beneficial. In this paper we present a computational tool that enables the fully automatic generation of skeletal models of the lower limb from three-dimensional bone geometries, normally obtained by segmentation of medical images. This tool was evaluated against four manually created lower limb models finding remarkable agreement in the computed joint parameters, well within human operator repeatability. The coordinate systems origins were identified with maximum differences between $0.5 \mathrm{~mm}$ (hip joint) and $5.9 \mathrm{~mm}$ (subtalar joint), while the joint axes presented discrepancies between $1^{\circ}$ (knee joint) to $11^{\circ}$ (subtalar joint). To prove the robustness of the methodology, the models were built from four datasets including both genders, anatomies ranging from juvenile to elderly and bone geometries reconstructed from high-quality computed tomography as well as lower-quality magnetic resonance imaging scans. The entire workflow, implemented in MATLAB scripting language, executed in seconds and required no operator intervention, creating lower extremity models ready to use for kinematic and kinetic analysis or as baselines for more advanced musculoskeletal modelling approaches, of which we provide some practical examples. We auspicate that this technical advancement, together with upcoming progress in medical image segmentation techniques, will promote the use of personalised models in larger-scale studies than those hitherto undertaken. (c) 2021 The Authors. Published by Elsevier Ltd. This is an open access article under the CC BY license (http://
\end{abstract} creativecommons.org/licenses/by/4.0/).

\section{Introduction}

Musculoskeletal models have proven to be powerful computational tools to study muscle function and internal forces in healthy (Hamner et al., 2010; Saxby et al., 2016) and clinical populations (Barber et al., 2017; Fox et al., 2018; Montefiori et al., 2019b). Recent technical progress in predictive simulation approaches (Dembia et al., 2019; Falisse et al., 2019) has enabled the investigation of "what if?" scenarios that could support planning and execution of physical interventions. However, applications of personalised medicine often require highly accurate representations of the anatomy of the musculoskeletal system based on medical images such as magnetic resonance imaging (MRI) or computed tomography (CT) scans. For example, personalized bone geometries are essential in orthopaedics for planning surgeries and

\footnotetext{
* Corresponding author at: Dept of Civil and Environmental Engineering, Skempton Building, Imperial College London, UK.

E-mail address: l.modenese@imperial.ac.uk (L. Modenese).
}

designing personalised surgical equipment (Clarke et al., 2018; Victor and Premanathan, 2013) and for creating subject-specific musculoskeletal models.

Previous studies presented methods to generate subjectspecific models of the entire lower limb (Marra et al., 2015; Modenese et al., 2018) or individual joints (Barzan et al., 2019; Brito da Luz et al., 2017; Montefiori et al., 2019a; Nardini et al., 2020) and dedicated modelling tools like NMSBuilder (Valente et al., 2017a) or specialized features in the AnyBody software (Damsgaard et al., 2006) are available to implement these workflows. Nevertheless, patient-specific musculoskeletal models are currently employed in small-sized clinical applications (Falisse et al., 2020; Montefiori et al., 2019b; Pitto et al., 2019; Taddei et al., 2012; Valente et al., 2017b), mostly because the generation of each model is a time-demanding operation requiring manual intervention by specialized operators. For example, a codified approach proposed in Modenese et al. (2018) reported around $10 \mathrm{~h}$ to build a complete bilateral musculoskeletal model of the lower limbs from segmented bone geometries (around two hours 
to create an ipsilateral skeletal model), while Scheys et al. (2006) reported on average $65 \mathrm{~min}$ to define the lower limb musculature using an atlas-based semi-automated approach. We believe that validated and fully automatic workflows are of paramount importance to enable large-scale use of these computational models.

Multiple studies with orthopaedic focus have explored the possibility of defining anatomical coordinate systems (ACSs) in the lower extremity bones based on key geometrical features. Miranda et al. (2010) and Rainbow et al. (2013) proposed automatic methods for defining ACSs for the distal femur, proximal tibia and patella, that showed minimum variability with the bone morphology. Kai et al. (2014) developed an automatic approach to identify the reference systems of the pelvis, femur and tibia based on principal axes of inertia, principal component analysis and longitudinal slicing, obtaining ACSs compatible with those created by human operators, except for the pelvis where anterior tilt was up to $18.8^{\circ}$ higher. More recently, Renault et al. (2018) proposed multiple algorithms based on the automatic identification of the articular surfaces at the hip and knee joints, showing high repeatability of these methods when applied on 24 CT scans by three operators. However, in these previous works the ACSs were not defined consistently across publications and none of these methods has been employed for creating articulated skeletal models yet.

Statistical shape modelling workflows have recently demonstrated high potential for reconstructing bone geometries from sparse anatomical datasets (Davico et al., 2019; Nolte et al., 2016; Suwarganda et al., 2019) and landmarks digitized in the gait lab (Nolte et al., 2020; Zhang et al., 2016), but to the best of the authors' knowledge they do not yet offer methods to generate articulated skeletal models of the complete lower limb. The bone reconstructions are limited to the long bones (Nolte et al., 2020; Nolte et al., 2016) or omit the talus and foot bones (Davico et al., 2019; Suwarganda et al., 2019; Zhang et al., 2016), and in musculoskeletal modelling contexts they have been employed to perform non-linear scaling of pre-existing muscle attachments (Nolte et al., 2016) with scarce focus towards joint modelling. Hence, a comprehensive approach to generate entire lower limb models from personalised bone geometries is still missing.

The aim of this paper is to present a tool to create models of the complete lower limb from three-dimensional bone geometries in a fully automatic way. The tool implements a sequence of operations normally performed in manual workflows, executes them in negligible computational time and generates models usable immediately in kinematic and kinetic analyses or employable as baselines for fully featured musculoskeletal models. The models produced by this tool were evaluated against manually created models employed in previous research and the joint parameters computed by competing algorithms were compared to assess their interchangeability. Differences in kinematics and kinetics curves calculated using manual and automated models were also preliminarily quantified on a set of gait simulations. Examples of further technical developments, such as joint articular mechanics and integration with anatomical models of musculature, are finally provided to demonstrate the tool's potential for enabling large-scale studies and broader musculoskeletal research.

\section{Materials and methods}

\subsection{Workflow to generate automatic skeletal models}

A set of computational methods proposed in previous literature to define ACSs automatically (Kai et al., 2014; Miranda et al., 2010; Renault et al., 2018) were acquired and included in a more extensive modelling workflow. The geometrical methods from Renault et al. (2018) were obtained from the public "GIBOC-KNEE” MATLAB toolbox (https://github.com/renault]B/GIBOC-Knee-CoordinateSystem) and extensively modified and expanded, while the methods described by Kai et al. (2014) were independently reimplemented and those of Miranda et al. (2010) were obtained through contacting the authors of the publication. Additional algorithms were developed ad hoc for the purposes of this investigation (Table 1).

The implemented workflow (Fig. 1) consisted of the following steps: a) obtaining segmented three-dimensional bone geometries of the pelvis, femur, patella, tibia, fibula, talus, calcaneus and the other foot bones from medical images; b) automatically processing these bone models to extract the geometrical parameters required to define ACSs and appropriate joint coordinate systems (JCSs) for the parent and child bodies of each joint of the lower limb; c) creating an articulated skeletal model of the lower limb in OpenSim format (Delp et al., 2007) using the identified JCSs and ACSs.

In step b), bone geometries were analysed starting with a transformation to the ACSs defined by their principal axes of inertia (Gonzalez-Ochoa et al., 1998; Mirtich, 1996), followed by bonespecific features extraction. The complete list of algorithms available to define each JCS is reported in Table 1 and the details of the methodologies are described in their reference publications, and for the newly developed algorithms for the pelvis, talus and foot, in the supplementary materials. The articulated skeletal models were generated leveraging the MATLAB (The MathWorks, Natick, MA, USA) application programming interface (API) of OpenSim 4.1 (Seth et al., 2018): a rigid body with appropriate inertial properties (McConville et al., 1980; Winter, 2009), was created for each leg segment and joints defined based on the JCSs identified at step c). The individual JCSs, consistent with Modenese et al. (2018), are described in Table 1. For convenience in the evaluation step, all rigid bodies shared a local coordinate system coincident with that of the medical images, as they would have in a model generated using NMSBuilder (Valente et al., 2017a). The lower limb models included five bodies: pelvis, femur, tibia (including fibula and a rigidly attached patella), talus and foot (including calcaneus and foot bones), and five joints: a free joint between pelvis and ground (6 degrees of freedom, or "DoF"), a ball and socket joint for the hip joint (3 rotational DoF) and hinge joints for the tibiofemoral, talocrural and subtalar joints (1 rotational DoF each). No explicit patellofemoral joint was included in the models. The models also included fourteen landmarks (Table 2) automatically identified on the bone surfaces and intended for registration with the skin markers used in standard gait analysis.

The entire set of scripts implementing this workflow was organized in a MATLAB toolbox named STAPLE (Shared Tools for Automatic Personalised Lower Extremity modelling).

\subsection{Evaluation of the automatic models}

The models produced using the automatic workflow were compared against musculoskeletal models of the lower limb generated for other purposes using NMSBuilder (manual models) and previously employed in published research (Montefiori et al., 2019b) or contributions at international conferences (Modenese et al., 2020; Modenese et al., 2019). These subject-specific models were built following the codified approach of Modenese et al. (2018) and using bone geometries available in public datasets plus an in vivo MRI dataset collected with the approval of the Imperial College Research Ethics Committee. A complete description of the datasets, characterized by quality of the bone geometry meshes ranging from very good (LHDL-CT) to low (JIA-MRI), is provided in Table 3 and Fig. 2.

Articulated skeletal models for all datasets were generated using the STAPLE toolbox (automatic models) and their JCSs com- 
Table 1

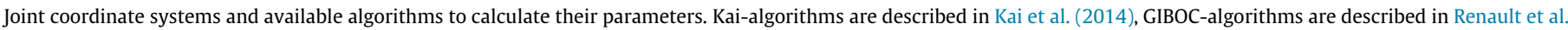

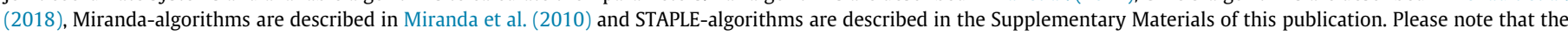

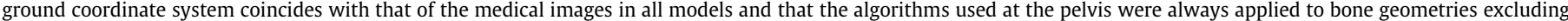

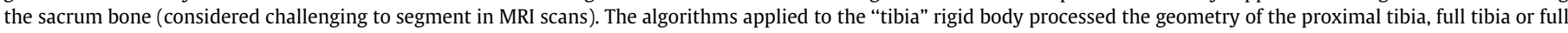

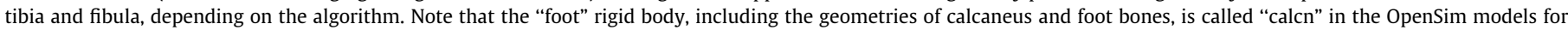
consistency with the other models included in the software distribution.

\begin{tabular}{|c|c|c|c|}
\hline $\begin{array}{l}\text { Rigid } \\
\text { Body }\end{array}$ & $\begin{array}{l}\text { Joint Coordinate } \\
\text { System }\end{array}$ & Algorithms & Description of joint coordinate systems used for validation (from Modenese et al. 2018) \\
\hline \multirow[t]{4}{*}{ pelvis } & ground-pelvis child & Kai-Pelvis & Origin: midpoint of ASIS. \\
\hline & & STAPLE-Pelvis & Axes: ISB recommendations for pelvis. \\
\hline & hip parent & $\mathrm{N} / \mathrm{A}$ & Origin: coincident with hip child origin. \\
\hline & & & Axes aligned with those of ground-pelvis child. \\
\hline \multirow[t]{7}{*}{ femur } & hip child & Kai-Femur & Origin: center of femoral head (hip joint center). \\
\hline & & GIBOC-Femur & Axes: defined as in ISB recommendations for femur. \\
\hline & knee parent & Kai-Femur & Origin: the knee joint center, as defined by selected algorithm. \\
\hline & & Miranda-Femur & Axes: $\mathrm{Z}$ axis is the medio-lateral axis as defined by the selected algorithm. \\
\hline & & GIBOC-Spheres & $\mathrm{Y}$ axis is perpendicular to $\mathrm{Z}$, lying in the same plane of $\mathrm{Z}$ and the hip joint center. \\
\hline & & GIBOC-Ellipsoids & $\mathrm{X}$ axis is perpendicular to $\mathrm{Y}$ and $\mathrm{Z}$. \\
\hline & & GIBOC-Cylinder & \\
\hline \multirow[t]{9}{*}{ tibia } & knee child & Kai-Tibia & Origin: coincident with knee parent origin. \\
\hline & & Miranda-Femur & Axes: $\mathrm{Z}$ axis aligned with medio-lateral axis of knee parent \\
\hline & & GIBOC-Ellipse & $\mathrm{Y}$ axis is perpendicular to $\mathrm{Z}$ lying in the same plane as talocrural-child origin \\
\hline & & GIBOC-Centroids & $\mathrm{X}$ axis is perpendicular to $\mathrm{Y}$ and $\mathrm{Z}$. \\
\hline & & GIBOC-Plateau & \\
\hline & talocrural parent & $\mathrm{N} / \mathrm{A}$ & Origin: coincident with the talocrural child. \\
\hline & & & Axes: $\mathrm{Z}$ is aligned with the $\mathrm{Z}$ axis of the talocrural child. \\
\hline & & & $\mathrm{Y}$ axis is perpendicular to $\mathrm{Z}$, lying in the same plane of $\mathrm{Z}$ and the knee joint center. \\
\hline & & & $\mathrm{X}$ axis is perpendicular to $\mathrm{Y}$ and $\mathrm{Z}$. \\
\hline \multirow[t]{7}{*}{ talus } & talocrural child & STAPLE-Talus & $\begin{array}{l}\text { Origin: point at midpoint of the length on the axis of the cylinder fitter to the talar trochlea articular } \\
\text { surface. }\end{array}$ \\
\hline & & & Axes: $\mathrm{Z}$ is the axis of the cylinder fitted to the talar trochlea articular surface. \\
\hline & & & $\mathrm{X}$ is perpendicular to $\mathrm{Z}$, lying on a plane parallel to the foot sole $\mathrm{XZ}$ plane. \\
\hline & subtalar parent & STAPLE-Talus & Origin: center of the sphere fitted to the articular surface of the talocalcaneal joint. \\
\hline & & & Axes: $\mathrm{Z}$ axis on the line from the center of sphere fitted to the talocalcaneal articular surface to that \\
\hline & & & fitted to the talonavicular articular surface. \\
\hline & & & $\begin{array}{l}\mathrm{Y} \text { Is perpenalcular to } \mathrm{Z} \text {, lying in the same plane or } Z \text { and the knee joint centre. } \\
\mathrm{X} \text { axis perpendicular to } \mathrm{Y} \text { and } \mathrm{Z} \text {. }\end{array}$ \\
\hline \multirow[t]{5}{*}{ foot } & subtalar child & $\mathrm{N} / \mathrm{A}$ & Origin and axes defined by subtalar parent. \\
\hline & foot sole (auxiliary) & STAPLE-Foot & Origin: most distal point of the calcaneus. \\
\hline & & & $\begin{array}{l}\text { Axes: } \mathrm{X} \text { axis pointing from the most caudal point on the talus to the midpoint of the most caudal points } \\
\text { on the } 1 \text { st and } 5 \text { th metatarsal heads. }\end{array}$ \\
\hline & & & $\mathrm{Y}$ axis perpendicular to the plane identified by the points defining $\mathrm{X}$. \\
\hline & & & $\mathrm{Z}$ axis is perpendicular to $\mathrm{X}$ and $\mathrm{Y}$. \\
\hline
\end{tabular}

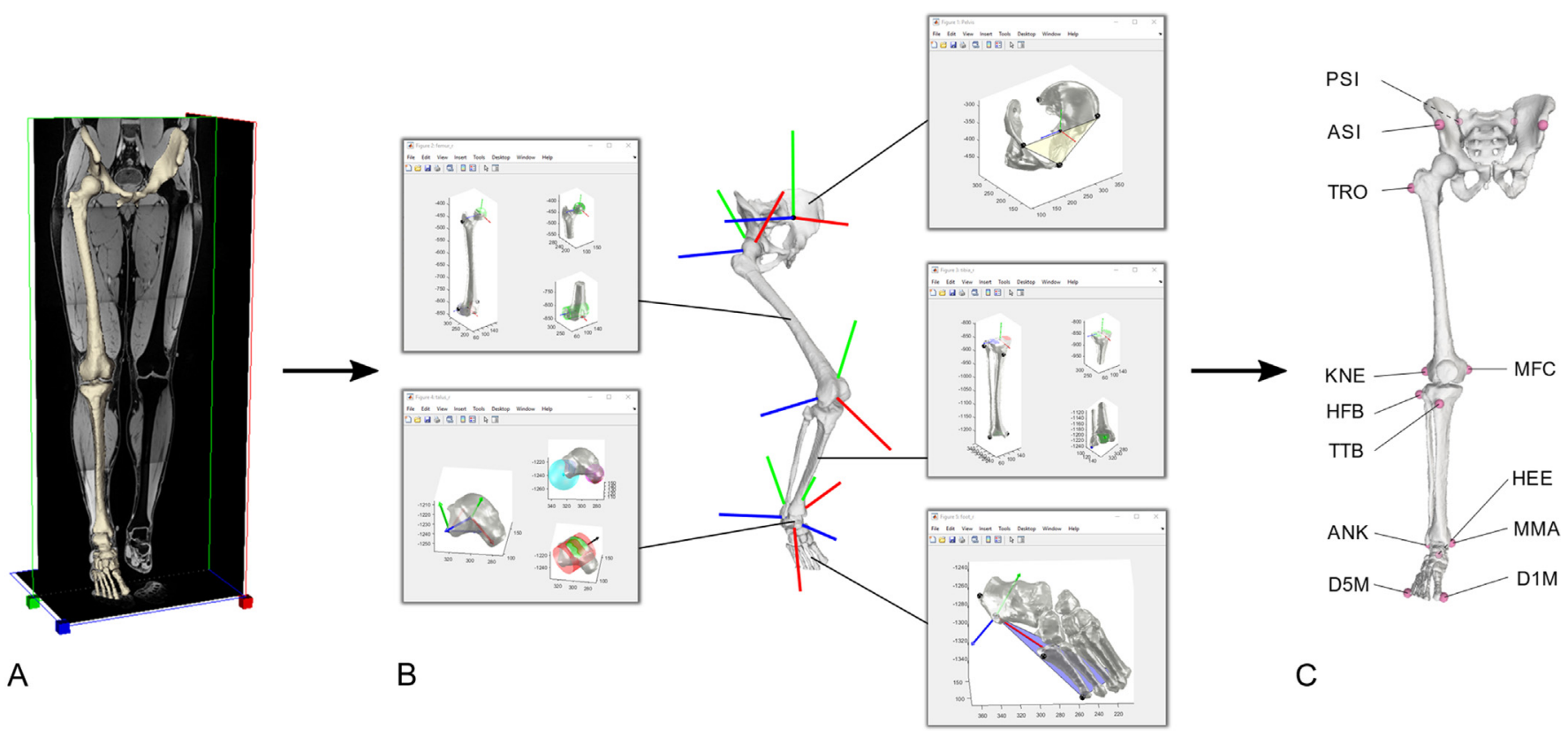

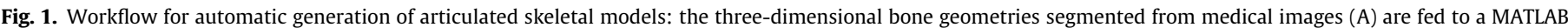

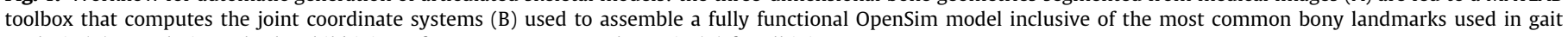
analysis (C). For clarity only the child joint reference systems are shown in (B) for all joints. 
Table 2

Landmarks identified on the three-dimensional bone geometries by the automated algorithms.

\begin{tabular}{lll}
\hline Rigid Body & Bony landmark & Description \\
\hline pelvis & RASI & Right anterior superior iliac spine \\
& LASI & Left anterior superior iliac spine \\
& RPSI & Right posterior superior iliac spine \\
& LPSI & Left posterior superior iliac spine \\
femur & TRO & Great trochanter \\
& MFC & Medial femoral epicondyle \\
& KNE & Lateral femoral epicondyle \\
tibia/fibula & MMA & Medial malleolus \\
& ANK & Lateral malleolus \\
& TTB & Tibial tuberosity \\
& HFB & Fibular head \\
foot & D1M & Head of first metatarsal bone \\
& D5M & Head of fifth metatarsal bone \\
& HEE & Heel \\
\hline
\end{tabular}

pared against those of the manual models, reporting differences in their origin location and axes orientation. These quantities were evaluated in the common global coordinate system of the medical images. The automatic models were created using algorithms that matched those of the manual approach (pelvis: STAPLE-Pelvis, femur: GIBOC-Cylinder, tibia: Kai-Tibia, talus: STAPLE-Talus and foot: STAPLE-Foot).

\subsection{Comparison of joint parameters estimated by different algorithms}

The JCSs of those joints for which more than one algorithm was available (ground-pelvis and knee joint) were then calculated using all the available options and the resulting JCSs compared to those employed in the evaluation part of the study, used as reference. Linear distances between origins and angular differences between axes were quantified and expressed in the JCS of the reference algorithm.

\subsection{Gait simulations using automatic and manual models}

The sensitivity of joint angles and net joint moments to JCS differences was quantified simulating six gait trials of JIA-MRI (Montefiori et al., 2019b) with the correspondent automatic and manual models, using the OpenSim inverse kinematic and inverse dynamic analyses. The resulting sets of curves were then compared using a Statistical Parametric Mapping (SPM) two-tailed $t$-test (significance level: $\alpha=0.05$ ) implemented in the spm1d package (Pataky, 2012). Correlation coefficients and root mean squared errors (RMSEs) were also calculated to compare individual trials.

\section{Results}

All the automatic models employed in the study were successfully generated in less than $30 \mathrm{~s}$ each using a standard Z640 Dell Workstation (RAM: 64 GB, CPU: 2 Intel Xeon E5-2630 $2.40 \mathrm{GHz}$ ).

The comparison of automatic and manual models (Table 4) resulted in an overall strong similarity of the joint parameters across all considered datasets. The hip and talocrural joint centres were in excellent agreement with the manual estimations (maximum differences hip: $0.5 \mathrm{~mm}$, talocrural: $1.2 \mathrm{~mm}$ ), whereas the maximum difference was $2.5 \mathrm{~mm}$ at the knee joint and $5.9 \mathrm{~mm}$ at the subtalar joint in the JIA-MRI model due to the low quality of bone reconstruction (difference range in the other datasets: 0.4-3.2 mm). The cranial-caudal position of the pelvis-ground joint origin differed by up to $4.9 \mathrm{~mm}$ (range: $0.8-4.9 \mathrm{~mm}$ ) causing minor differences in pelvic tilt (range: $1.8^{\circ}-3.6^{\circ}$, Fig. $3-\mathrm{A}$ ) that propagated to the hip-parent JCS. The axes of the knee and talocrural hinge joints (medio-lateral $Z$ axes) were estimated with maximum differences from manual models of $1.0^{\circ}$ degree, while the subtalar joint axes presented maximum differences up to $2.9^{\circ}$ in the datasets with good quality bone geometries but reached $11.3^{\circ}$ in the JIAMRI model (Fig. 3-B).

Table 3

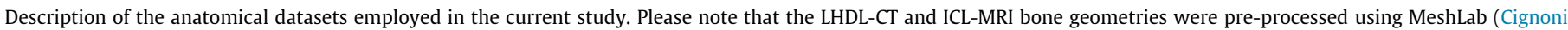

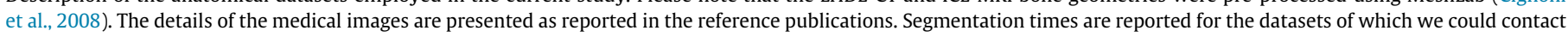
the curators.

\begin{tabular}{|c|c|c|c|c|c|c|c|c|c|c|}
\hline Dataset & Gender & Age & $\begin{array}{l}\text { Height } \\
\text { [m] }\end{array}$ & $\begin{array}{l}\text { Mass } \\
{[\mathbf{k g}]}\end{array}$ & $\begin{array}{l}\text { MSK } \\
\text { conditions }\end{array}$ & $\begin{array}{l}\text { Imaging } \\
\text { type }\end{array}$ & Details of medical images & $\begin{array}{l}\text { Bone segmentation } \\
\text { [approach: time] }\end{array}$ & $\begin{array}{l}\text { Quality } \\
\text { of bone } \\
\text { geometry }\end{array}$ & $\begin{array}{l}\text { Reference } \\
\text { publication } \\
\text { (R)/previous } \\
\text { use in the } \\
\text { authors' } \\
\text { work (U) }\end{array}$ \\
\hline LHDL-CT & $\mathrm{F}$ & 78 & 1.71 & 64 & No & $\mathrm{CT}$ & $\begin{array}{l}\text { CT scans collected with Siemens } \\
\text { Sensation } 64 \text {, pixel spacing and slice } \\
\text { thickness: } \\
0.98 \mathrm{~mm} \times 0.98 \mathrm{~mm} \times 1.0 \mathrm{~mm} \text {, } \\
1 \mathrm{~mm} \text { slice spacing. }\end{array}$ & Manual: N/A & $\begin{array}{l}\text { Very } \\
\text { Good }\end{array}$ & $\begin{array}{l}\text { R:(Viceconti } \\
\text { et al., 2008) } \\
\text { U: Modenese } \\
\text { et al. (2016, } \\
\text { 2019, 2020) }\end{array}$ \\
\hline TLEM2-CT & M & 85 & $\mathrm{~N} / \mathrm{A}$ & $45^{*}$ & No & $\mathrm{CT}$ & $\begin{array}{l}\text { CT scans collected with Siemens } \\
\text { SOMATOM }^{\circledR} \text { Sensation } 16 \mathrm{CT} \\
\text { Scanner, voxel size of } \\
0.977 \mathrm{~mm} \times 0.977 \mathrm{~mm} \times 0.75 \mathrm{~mm} \text {. }\end{array}$ & Manual: $<8$ h (bilateral) & Good & $\begin{array}{l}\text { R: (Carbone } \\
\text { et al., 2015) } \\
\text { U: Modenese } \\
\text { et al. (2019) }\end{array}$ \\
\hline ICL-MRI & M & 38 & 1.80 & 87 & No & MRI & $\begin{array}{l}\text { MRI scans collected with a } 3 \mathrm{~T} \\
\text { Siemens Verio, 3D T1-weighted } \\
\text { VIBE, axial field of view: } 450 \times 450 \\
\text { mm, pixel size: } 1.41 \times 1.41 \mathrm{~mm} \text {, } \\
\text { slice thickness and increment: } \\
1 \mathrm{~mm}\end{array}$ & $\begin{array}{l}\text { Semi-automatic: } \approx 2 \mathrm{~h} \\
\text { (Yushkevich et al. } \\
\text { 2006) }\end{array}$ & Average & $\begin{array}{l}\text { R/U: } \\
\text { Modenese } \\
\text { et al. (2020) }\end{array}$ \\
\hline JIA-MRI** & M & 14 & 1.74 & 76.5 & $\mathrm{JIA}^{* * *}$ & MRI & $\begin{array}{l}\text { 3D T1-weighted fat-suppression } \\
\text { sequence (e-THRIVE) with } 1 \mathrm{~mm} \text { in- } \\
\text { plane resolution and } 1 \mathrm{~mm} \text { slice } \\
\text { thickness. }\end{array}$ & $\begin{array}{l}\text { Statistical Shape } \\
\text { Modelling: N/A } \\
\text { (Steger et al., 2012) }\end{array}$ & Low & $\begin{array}{l}\text { R/U: } \\
\text { Montefiori } \\
\text { et al. 2019b }\end{array}$ \\
\hline
\end{tabular}

* estimated by Carbone et al. (2015).

** the OpenSim model, but not the medical images, is available with the reference publication.

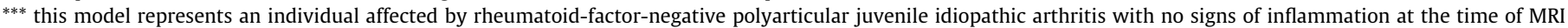
scans (patient P3 in Montefiori et al. 2019b). 

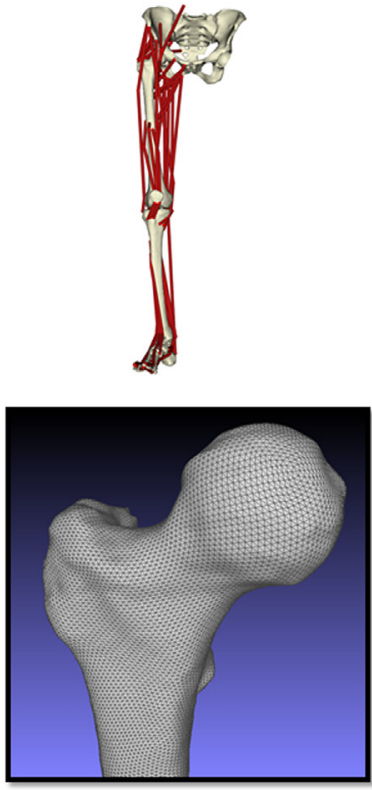

LHDL-CT
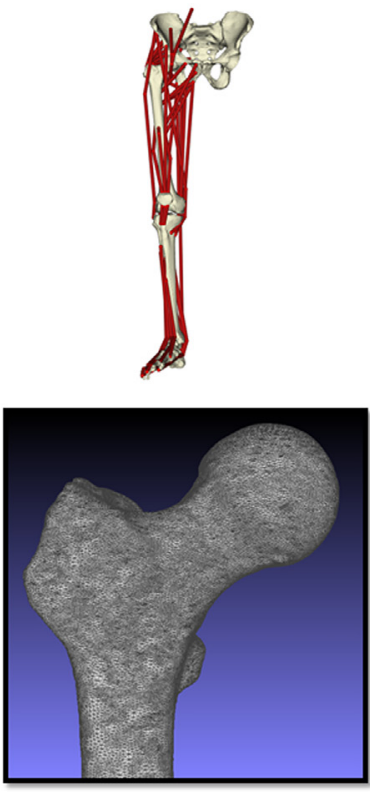

TLEM2-CT
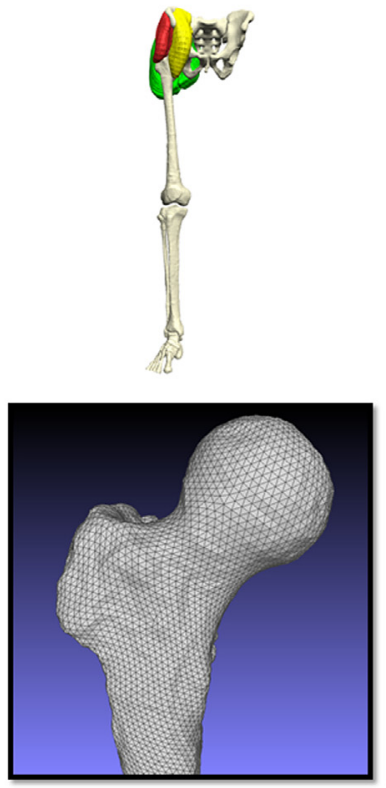

ICL-MRI
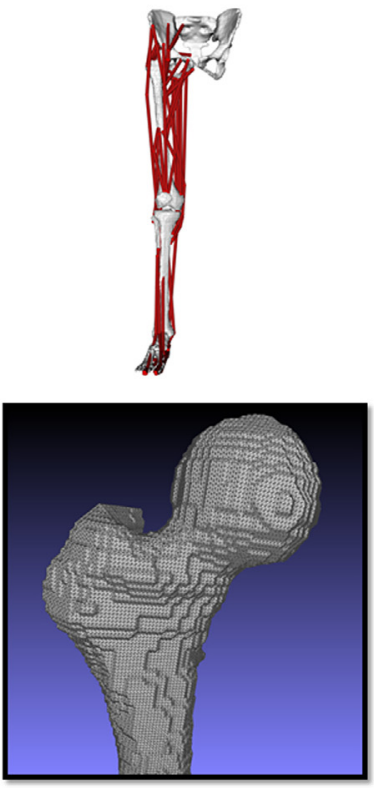

JIA-MRI

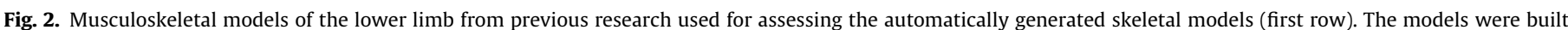
using bone reconstructions of variable quality (second row). Details about these models are available in Table 3.

Table 4

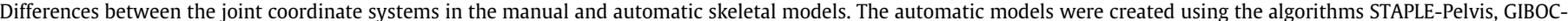

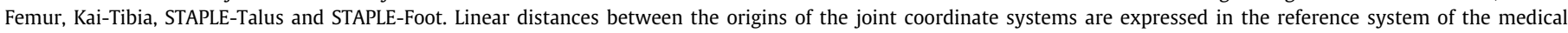

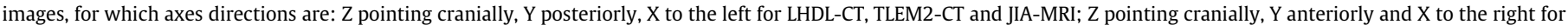
ICL-MRI.

\begin{tabular}{|c|c|c|c|c|c|c|c|c|c|c|c|}
\hline \multirow[t]{2}{*}{ Dataset } & \multirow[t]{2}{*}{ Joint } & \multicolumn{4}{|c|}{ Origin displacement vector [mm] } & \multicolumn{3}{|c|}{$\begin{array}{l}\text { Axes Differences - Parent } \\
\text { [deg] }\end{array}$} & \multicolumn{3}{|c|}{$\begin{array}{l}\text { Axes Differences - Child } \\
\text { [deg] }\end{array}$} \\
\hline & & $\mathbf{X}$ & $\mathbf{Y}$ & $\mathbf{Z}$ & norm & $\mathbf{X}$ & $\mathbf{Y}$ & $\mathbf{Z}$ & $\mathbf{X}$ & $\mathbf{Y}$ & $\mathbf{Z}$ \\
\hline \multirow[t]{5}{*}{ LHDL-CT } & pelvis-ground & -0.7 & 0.8 & -3.0 & 3.1 & 0.0 & 0.0 & 0.0 & 3.1 & 3.4 & 1.2 \\
\hline & hip & -0.2 & -0.2 & 0.2 & 0.3 & 3.1 & 3.4 & 1.2 & 0.7 & 0.2 & 0.7 \\
\hline & knee & -0.8 & 1.0 & 0.2 & 1.3 & 0.7 & 0.4 & 0.7 & 0.6 & 0.4 & 0.7 \\
\hline & talocrural & 0.1 & 0.3 & -0.9 & 0.9 & 0.2 & 0.4 & 0.5 & 1.7 & 1.7 & 0.5 \\
\hline & subtalar & -0.3 & 0.3 & 0.0 & 0.4 & 0.8 & 2.6 & 2.7 & 0.8 & 2.6 & 2.7 \\
\hline \multirow[t]{5}{*}{ TLEM2-CT } & pelvis-ground & -1.0 & 0.2 & -4.9 & 5.0 & 0.0 & 0.0 & 0.0 & 3.4 & 3.5 & 0.9 \\
\hline & hip & -0.1 & -0.1 & 0.2 & 0.3 & 3.4 & 3.5 & 0.9 & 0.1 & 0.2 & 0.2 \\
\hline & knee & 1.0 & -0.3 & 0.2 & 1.1 & 0.1 & 0.2 & 0.2 & 0.2 & 0.3 & 0.2 \\
\hline & talocrural & 0.1 & -0.9 & 0.4 & 1.0 & 0.7 & 0.7 & 1.0 & 1.9 & 1.6 & 1.0 \\
\hline & subtalar & -0.1 & 1.0 & -0.1 & 1.0 & 0.3 & 2.1 & 2.0 & 0.3 & 2.1 & 2.0 \\
\hline \multirow[t]{5}{*}{ ICL-MRI } & pelvis-ground & -0.5 & 0.0 & 0.8 & 0.9 & 0.0 & 0.0 & 0.0 & 1.8 & 2.0 & 1.0 \\
\hline & hip & 0.0 & 0.1 & 0.1 & 0.1 & 1.8 & 2.0 & 1.0 & 0.1 & 2.0 & 2.0 \\
\hline & knee & 2.0 & 0.5 & 1.4 & 2.5 & 0.1 & 0.1 & 0.1 & 0.2 & 0.2 & 0.1 \\
\hline & talocrural & 0.7 & -0.6 & 0.0 & 0.9 & 0.3 & 0.4 & 0.4 & 2.5 & 2.6 & 0.4 \\
\hline & subtalar & -0.2 & -2.8 & -1.4 & 3.2 & 0.3 & 2.9 & 2.9 & 0.3 & 2.9 & 2.9 \\
\hline \multirow[t]{5}{*}{ JIA-MRI } & pelvis-ground & 0.5 & 1.0 & -4.4 & 4.5 & 0.0 & 0.0 & 0.0 & 3.4 & 3.6 & 1.0 \\
\hline & hip & -0.2 & 0.1 & -0.4 & 0.5 & 3.4 & 3.6 & 1.0 & 0.9 & 0.1 & 0.9 \\
\hline & knee & 0.3 & -0.2 & -1.0 & 1.1 & 0.9 & 0.1 & 0.9 & 0.9 & 0.1 & 0.9 \\
\hline & talocrural & -0.2 & 0.1 & 1.2 & 1.2 & 3.0 & 3.0 & 0.2 & 2.1 & 2.1 & 0.2 \\
\hline & subtalar & -1.4 & -0.4 & -5.7 & 5.9 & 2.2 & 11.3 & 11.3 & 2.2 & 11.3 & 11.3 \\
\hline
\end{tabular}

When comparing competing algorithms, we observed that differences among their JCSs were not always negligible (Table 5). The Kai-Pelvis algorithm presented larger pelvic tilt offsets than STAPLE-Pelvis, while GIBOC-Spheres provided the knee-parent JCSs closest to the reference algorithm (differences $<1^{\circ}$ for all cases except JIA-MRI). Kai-Femur and GIBOC-Ellipsoid resulted in more posteriorly and anteriorly located JCSs respectively, with maximum angular differences for the knee joint axis up to $4.7^{\circ}$ (LHDL-CT) for the former and $5.2^{\circ}$ (TLEM2-CT) for the latter. At the proximal tibia, all GIBOC algorithms computed more proximal origins than Kai-Tibia's (range: $5.8-12.5 \mathrm{~mm}$ ), with angular differences in the range $0.5^{\circ}-11.5^{\circ}$ for the medio-lateral axis but smaller for the proximal-distal axis (range: $0.9^{\circ}-2.9^{\circ}$ ). Overall, GIBOC-Plateau and Miranda-Tibia, which failed processing TLEM2-CT, identified similar JCSs, as expected by very similar algorithms. The JCSs from GIBOC-Ellipse and GIBOC-Centroids were also found more similar to each other than to the KaiTibia reference. 


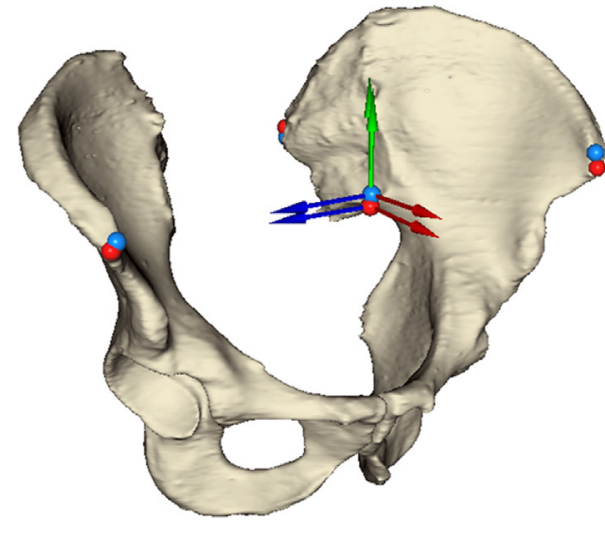

A

O MANUAL OAUTOMATIC

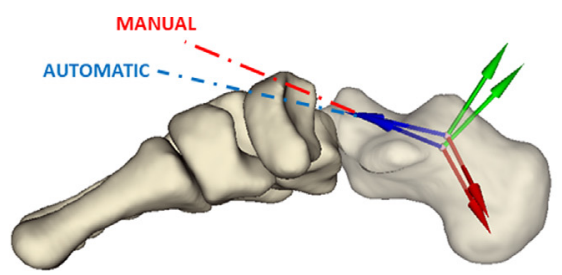

B

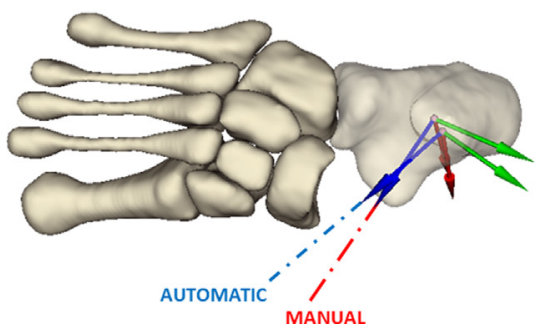

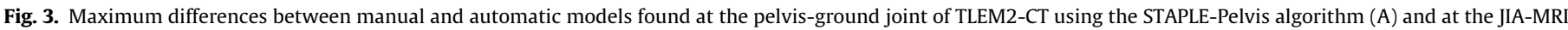
subtalar joint using the STAPLE-Talus algorithm (B).

Table 5

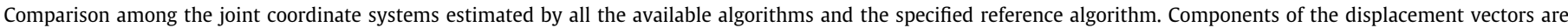

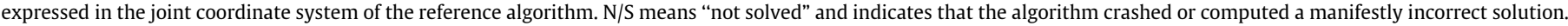

\begin{tabular}{|c|c|c|c|c|c|c|c|c|c|}
\hline \multirow[t]{2}{*}{ Joint Coordinate System [Reference Algorithm] } & \multirow[t]{2}{*}{ Algorithm } & \multirow[t]{2}{*}{ Dataset } & \multicolumn{4}{|c|}{ Origin displacement vector $[\mathrm{mm}]$} & \multicolumn{3}{|c|}{ Axes Differences [deg] } \\
\hline & & & $\mathbf{X}$ & $\mathbf{Y}$ & $\mathbf{Z}$ & norm & $\mathbf{X}$ & $\mathbf{Y}$ & $\mathbf{Z}$ \\
\hline ground-pelvis-child & Kai-Pelvis & LHDL-CT & -0.4 & 5.7 & 0.5 & 5.7 & 2.3 & 2.4 & 0.8 \\
\hline \multirow[t]{3}{*}{ [STAPLE-Pelvis] } & & TLEM2-CT & -0.2 & 1.1 & -0.2 & 1.1 & 0.5 & 0.7 & 0.5 \\
\hline & & ICL-MRI & -1.3 & 5.8 & -0.1 & 6.0 & 2.1 & 2.4 & 1.3 \\
\hline & & JIA-MRI & -0.1 & 0.4 & 0.1 & 0.4 & 0.2 & 0.2 & 0.2 \\
\hline Knee-parent & Miranda-Femur* & LHDL-CT & 0.6 & -1.4 & -0.2 & 1.6 & 2.9 & 2.6 & 1.5 \\
\hline \multirow[t]{15}{*}{ [GIBOC-Cylinder] } & & TLEM2-CT & -3.2 & -1.7 & 0.4 & 3.7 & 0.7 & 0.9 & 0.6 \\
\hline & & ICL-MRI & $\mathrm{N} / \mathrm{S}$ & $\mathrm{N} / \mathrm{S}$ & $\mathrm{N} / \mathrm{S}$ & $\mathrm{N} / \mathrm{S}$ & $\mathrm{N} / \mathrm{S}$ & $\mathrm{N} / \mathrm{S}$ & $\mathrm{N} / \mathrm{S}$ \\
\hline & & JIA-MRI & $\mathrm{N} / \mathrm{S}$ & $\mathrm{N} / \mathrm{S}$ & $\mathrm{N} / \mathrm{S}$ & $\mathrm{N} / \mathrm{S}$ & $\mathrm{N} / \mathrm{S}$ & $\mathrm{N} / \mathrm{S}$ & $\mathrm{N} / \mathrm{S}$ \\
\hline & Kai-Femur & LHDL-CT & -2.4 & -0.3 & 0.9 & 2.5 & 3.6 & 3.0 & 4.7 \\
\hline & & TLEM2-CT & -3.8 & -0.8 & 0.6 & 4.0 & 3.0 & 0.6 & 3.0 \\
\hline & & ICL-MRI & -3.8 & -1.0 & -0.1 & 3.9 & 3.6 & 2.8 & 4.5 \\
\hline & & JIA-MRI & -3.6 & -1.1 & 0.0 & 3.7 & 1.9 & 1.5 & 2.2 \\
\hline & GIBOC-Spheres & LHDL-CT & 0.0 & -0.5 & 1.4 & 1.5 & 0.1 & 0.1 & 0.1 \\
\hline & & TLEM2-CT & 0.9 & 0.1 & 2.0 & 2.2 & 0.2 & 0.2 & 0.2 \\
\hline & & ICL-MRI & 0.0 & -0.6 & 1.3 & 1.4 & 0.6 & 0.5 & 0.8 \\
\hline & & JIA-MRI & -1.3 & -1.4 & 2.2 & 2.8 & 5.0 & 4.6 & 6.7 \\
\hline & GIBOC-Ellipsoids & LHDL-CT & 9.1 & 1.2 & 1.2 & 9.3 & 4.4 & 2.3 & 4.5 \\
\hline & & TLEM2-CT & 8.6 & -0.4 & 2.0 & 8.8 & 4.4 & 3.6 & 5.2 \\
\hline & & ICL-MRI & 9.0 & 0.4 & 1.6 & 9.2 & 3.6 & 1.9 & 3.6 \\
\hline & & JIA-MRI & 7.8 & 1.2 & 2.1 & 8.1 & 2.6 & 3.0 & 3.4 \\
\hline Knee-child & Miranda-Tibia $^{* *}$ & LHDL-CT & -0.1 & 7.5 & -1.7 & 7.7 & 10.9 & 7.0 & 9.9 \\
\hline \multirow[t]{15}{*}{ [Kai-Tibia] } & & TLEM2-CT & $\mathrm{N} / \mathrm{S}$ & $\mathrm{N} / \mathrm{S}$ & $\mathrm{N} / \mathrm{S}$ & $\mathrm{N} / \mathrm{S}$ & $\mathrm{N} / \mathrm{S}$ & $\mathrm{N} / \mathrm{S}$ & $\mathrm{N} / \mathrm{S}$ \\
\hline & & ICL-MRI & -0.5 & 8.7 & -1.5 & 8.8 & 7.8 & 5.4 & 5.7 \\
\hline & & JIA-MRI & 0.6 & 0.3 & 0.5 & 0.8 & 4.4 & 3.8 & 2.9 \\
\hline & GIBOC-Plateau & LHDL-CT & -1.7 & 10.4 & -1.2 & 10.6 & 9.3 & 1.7 & 9.1 \\
\hline & & TLEM2-CT & -0.9 & 10.3 & -1.6 & 10.5 & 2.7 & 0.9 & 2.6 \\
\hline & & ICL-MRI & -1.8 & 12.5 & -2.2 & 12.9 & 6.0 & 1.8 & 5.8 \\
\hline & & JIA-MRI & -1.4 & 6.2 & -1.3 & 6.5 & 5.4 & 1.4 & 5.2 \\
\hline & GIBOC-Ellipse & LHDL-CT & -3.5 & 10.1 & -2.1 & 10.9 & 2.8 & 2.1 & 1.9 \\
\hline & & TLEM2-CT & -2.6 & 10.0 & -2.8 & 10.7 & 4.0 & 1.2 & 3.8 \\
\hline & & ICL-MRI & -4.9 & 12.1 & -2.7 & 13.3 & 2.6 & 2.3 & 1.3 \\
\hline & & JIA-MRI & -4.5 & 5.8 & 0.1 & 7.4 & 6.7 & 2.0 & 6.4 \\
\hline & GIBOC-Centroids & LHDL-CT & -2.1 & 10.4 & -1.6 & 10.7 & 1.9 & 1.8 & 0.5 \\
\hline & & TLEM2-CT & -2.4 & 10.0 & -1.5 & 10.4 & 2.3 & 1.2 & 2.0 \\
\hline & & ICL-MRI & -8.7 & 11.7 & -2.8 & 14.8 & 4.2 & 2.9 & 3.2 \\
\hline & & JIA-MRI & -3.3 & 6.0 & 0.0 & 6.9 & 11.7 & 1.8 & 11.5 \\
\hline
\end{tabular}

* Miranda-Femur crashed when processing JIA-MRI and fitted the shaft of the femur of ICL-MRI.

*** Miranda-Tibia identified inverted axes direction for TLEM2-CT and was not able to process the JIA-MRI tibial geometry unless the fibula was included as well.

The joint angles from the walking simulations performed with the manual and automatic JIA-MRI models (Fig. 4) presented correlation coefficients greater than $0.99(\mathrm{p}<0.0001)$ and RMSE $\approx 1^{\circ}$ degree for all coordinates except pelvis tilt and hip flex/extension, for which these errors $\left(3.4^{\circ}\right)$ were consistent with the JCS offsets in the sagittal plane (Table 4). The SPM $t$-test returned significant dif- 

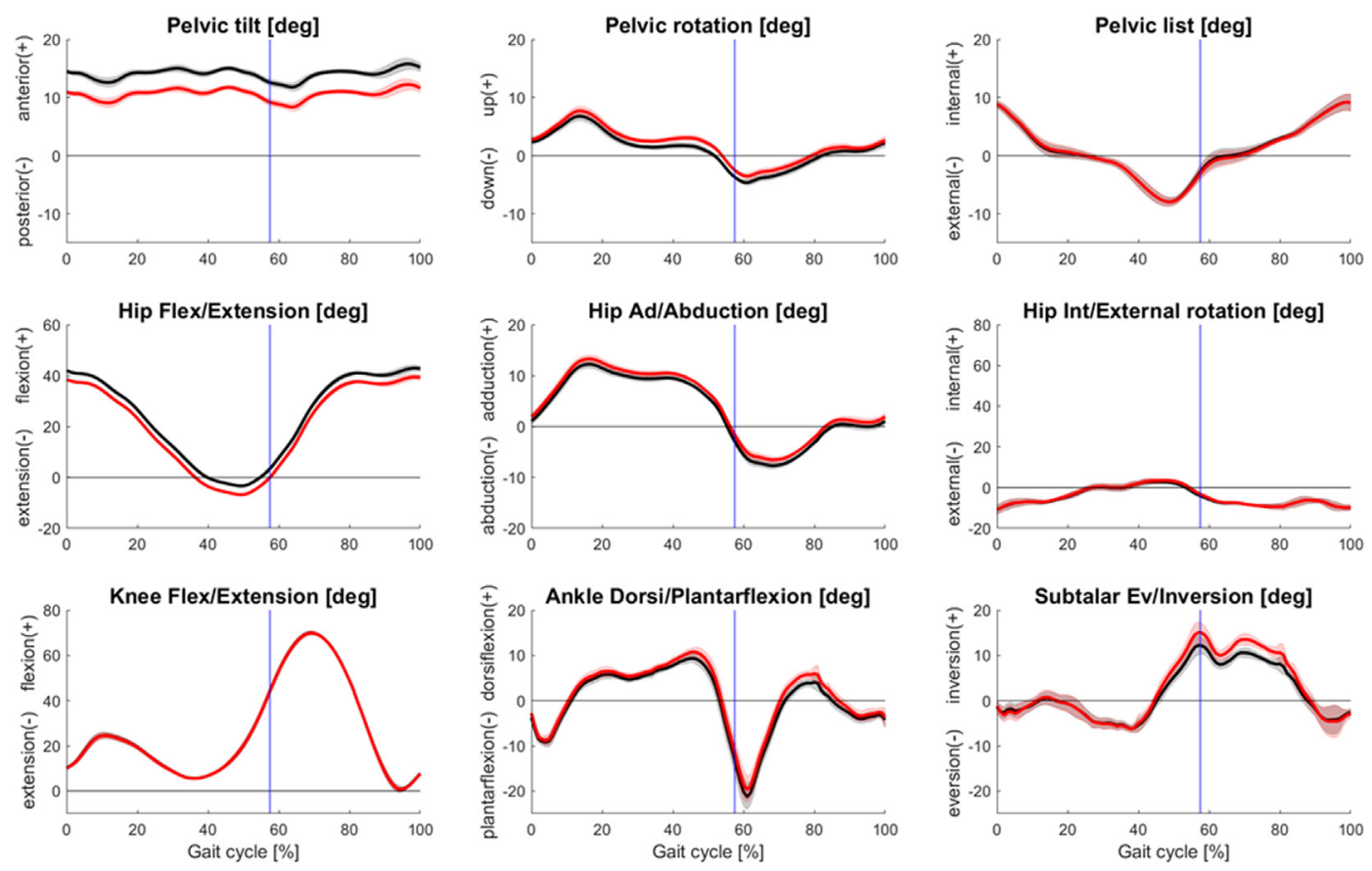

Automatic Model Manual Model

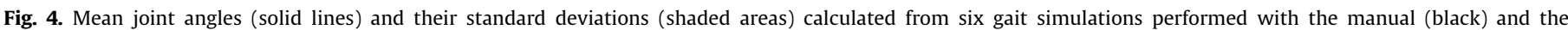

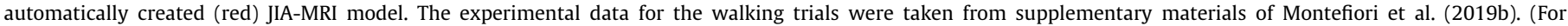
interpretation of the references to colour in this figure legend, the reader is referred to the web version of this article.)
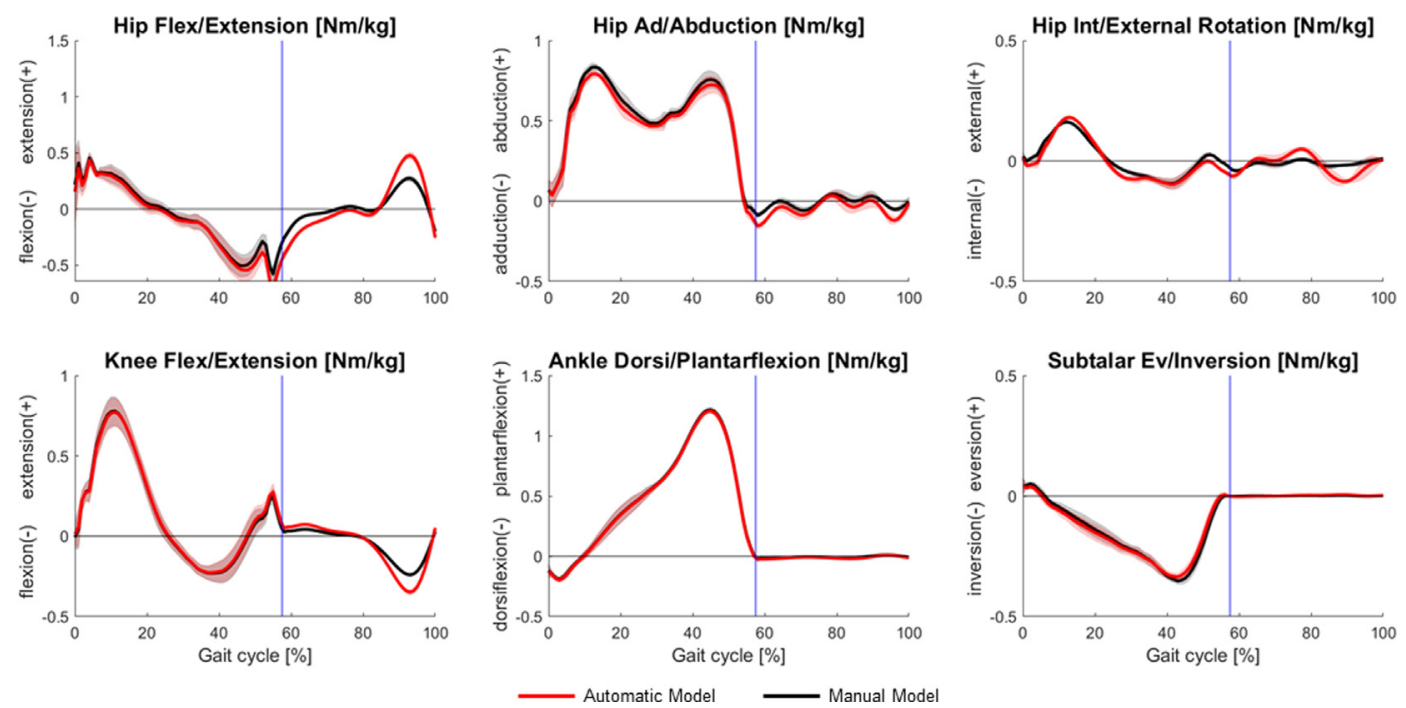

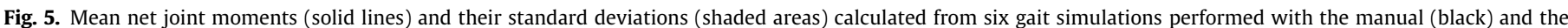

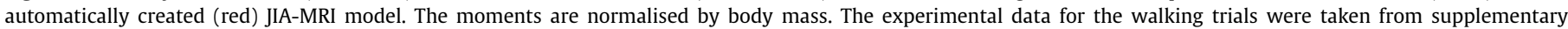
materials of Montefiori et al. (2019b). (For interpretation of the references to colour in this figure legend, the reader is referred to the web version of this article.)

ferences between the kinematics curves only for small portions of the gait cycle (from $0 \%$ to $13 \%$ ), except for pelvis tilt and hip flex/ extension $(\approx 100 \%)$ and pelvic rotation $(32 \%)$. The joint moments (Fig. 5) had correlation coefficients larger than 0.94 ( $p<0.0001$ ) and mean RMSE ranging from 0.078 (hip flex/extension) to 0.007 $\mathrm{Nm} / \mathrm{Kg}$ (ankle dorsi/plantarflexion). Significant differences between the curve sets were observed mostly in the swing phase of gait, where the inertial effects were more pronounced, in clusters ranging from $11 \%$ to $37 \%$ of the gait cycle. Detailed SPM plots are available in the supplementary materials.

\section{Discussion}

The aim of this paper was to present a tool to automatically create personalised models of the lower limb from three-dimensional bone geometries segmented in medical images. To evaluate the proposed methodology, we generated four automatic models and compared them against models manually created from the same data in other research projects. We found that the automatic and manual models were remarkably similar (Table 4), with largest differences observed for the pelvis-ground and subtalar joints. In the 
pelvis, the JCS origin was misplaced by up to $4.9 \mathrm{~mm}$ cranially due to the identified bony landmarks (Fig. 3-A). This difference caused a systematic anterior tilt offset in the range $1.8^{\circ}-3.6^{\circ}$ that propagated to the pelvis and hip joint kinematics, as confirmed by the gait simulations. Although not negligible, this offset represents a substantial improvement (almost $15^{\circ}$ ) compared to the results of Kai et al. (2014). More recent algorithms, e.g. Fischer et al. (2019), could be considered for future additional comparisons. The automatic subtalar joint axis in the JIA-MRI dataset was also noticeably different from the equivalent manual model $\left(11.3^{\circ}\right.$, Fig. 3-B). This discrepancy was attributed to the low-quality talus bone reconstruction since in all the other models the same axis was estimated within $2.9^{\circ}$.

JCS differences at the hip, knee and talocrural joint were well within the ranges of human inter-operator repeatability reported as standard deviations in previous investigations (Hannah et al., 2017; Martelli et al., 2015; Montefiori et al., 2019b) and even the largest difference observed at the subtalar axis was close to the maximum inter-operator variability $\left(9.6^{\circ}\right)$ reported by Montefiori et al. (2019a). These JCSs differences caused joint angles offsets in the gait simulations, as expected based on previous studies (Kainz et al., 2016; Martelli et al., 2014; Montefiori et al., 2019b; Valente et al., 2014). The largest difference in net joint moments (Fig. 5) occurred for the hip flex/extension moment in the swing phase of gait and was attributed to dissimilar shank mass between models (25\% difference), based on the results of Wesseling et al. (2014). This discrepancy was due to the inertial properties being estimated using segmented soft tissues geometries (not publicly available) in the manual JIA-MRI model (Montefiori et al., 2019b) and using regression equations (McConville et al., 1980; Winter, 2009) in the automatic model. It is worth highlighting that simulation results from the STAPLE models will have zero inter- and intra-operator variability due to model construction.

In all considered models, the JCSs were created as in Modenese et al. (2018), but other algorithms were also assessed (Table 1) to encourage researchers to implement different modelling workflows. At the pelvis, using Kai-Pelvis instead of STAPLE-Pelvis resulted in larger pelvis tilt offsets. For the long bones, JCSs estimated by different algorithms exhibited variability comparable with Renault et al. (2018). At the distal femur the differences among JCSs were small ( $<5^{\circ}$ in the $93 \%$ of estimations) but not negligible, therefore the choice of the algorithm, e.g. fitting ellipsoids (Sholukha et al., 2011) or spheres (Yin et al., 2015) to the femoral condyles articular surface, must be justified with careful functional anatomy considerations relevant to the research question. At the proximal tibia, the mechanical axis ( $\mathrm{Y}$ axis) was similar between Kai-Tibia and GIBOC algorithms (range: $0.9^{\circ}-2.9^{\circ}$ ) but less for Miranda-Tibia (up to $7^{\circ}$ ). Larger differences were observed in the medio-lateral axis (range: $0.5^{\circ}-11.5^{\circ}$ ) and anterior-posterior axis (range: $1.9^{\circ}-11.7^{\circ}$ ). The workflow of Modenese et al. (2018) connects the tibia to the tibiofemoral axis identified in the femur in the segmented pose, hence when the knee joint assumes the neutral position with zero flexion/extension angle, offsets due to standard supine imaging (Hirschmann et al., 2015) could still be present. The automatic algorithms could inform procedures to adjust the tibiofemoral alignment, but further work is required in this respect.

A current limitation of the study is that our evaluation datasets were only four, and despite their heterogeneity, did not include bone geometries presenting abnormalities, deformities and partial geometries due to imaging (Henckel et al., 2006) or amputations that could be encountered clinically. This limitation is mitigated by the availability of multiple algorithms for the long bones, some of which specifically developed for incomplete geometries (Miranda et al., 2010; Renault et al., 2018), but addi- tional validation is undoubtedly required. Also, the quality of the bone geometries can vary depending on the medical image modality and their specifications and resolution, potentially affecting the automatic algorithms. This possibility was not systematically investigated in this study, although we can report that, when processing low quality bone models, algorithms based on bone global geometrical features (Kai-algorithms) were generally more robust than those relying on the identification of the articular surfaces (GIBOC-algorithms), while the Mirandaalgorithms seemed the most affected and failed to process some of the datasets.

The importance of a fully automatic approach as a step towards clinical application of modelling can be fully appreciated considering the reduction in total processing time for generating a skeletal model, from segmentation of the medical images to the final OpenSim model. For the ipsilateral models considered in this study, the bone segmentation and manual modelling steps required a comparable time (between two and four hours each, depending on the experience of the operator). For example, an expert operator segmented the ICL-MRI dataset, the only one that we processed directly, in around two hours using the semi-automatic functionalities of ITK-Snap (Yushkevich et al., 2006) and created an ipsilateral skeletal model in roughly the same amount of time. Based on the TLEM2 segmentation time (Table 3), our previous experience (Renault et al., 2018) and literature reports (Matsiushevich et al., 2019), we estimated similar processing times also for CT datasets. STAPLE executes modelling workflows in seconds, therefore practically halving the total processing time to generate a skeletal model and reducing it essentially to an image segmentation task. This means, for example, that when radiological scans are collected and segmented for planning musculoskeletal surgical interventions, obtaining further model-based biomechanical analyses becomes a quick and inexpensive option. Considering that deep learning techniques are reducing also the segmentation time by order of magnitudes, e.g. Noguchi et al. (2020) reported $\sim 12 \mathrm{~s}$ for segmenting a full-body CT scan of $\sim 600$ slices, the generation of personalised lower limb models in a number of clinical applications appears technically feasible.

The STAPLE toolbox is intentionally modular and can automate the generation of entire or partial lower limb models (see supplementary materials for examples). Moreover, the GIBOC and STAPLE algorithms provide a large amount of anatomical information such as articular surfaces (Fig. 6-A) and bone profiles that can be used for implementing more advanced joint models than those proposed here, e.g. contact models (Brandon et al., 2017; Conconi et al., 2015) or parallel mechanisms (Sancisi and Parenti-Castelli, 2011).

Extending skeletal models with models of muscle anatomy can also be completely automated (Modenese and Kohout, 2020). In a previous contribution (Modenese et al., 2020) we have used a non-rigid iterative closest point registration (Audenaert et al., 2019) to map the muscle attachment areas from a cadaveric dataset to the ICL-MRI participant's bones, generating highly-discretized, personalised muscle representations from segmented muscle geometries and simulating their kinematics during gait (Fig. 6-B). Future efforts will focus on streamlining these methodologies towards a comprehensive, fully automated, modelling tool for generating subject-specific musculoskeletal models.

In summary, this work presents a computational tool enabling researchers to generate articulated, subject-specific skeletal models of the lower limb in negligible time through a completely automatic workflow that takes three-dimensional bone geometries as inputs. These models can be used immediately for kinematic and kinetic analyses or can serve as extendable baselines for complete 

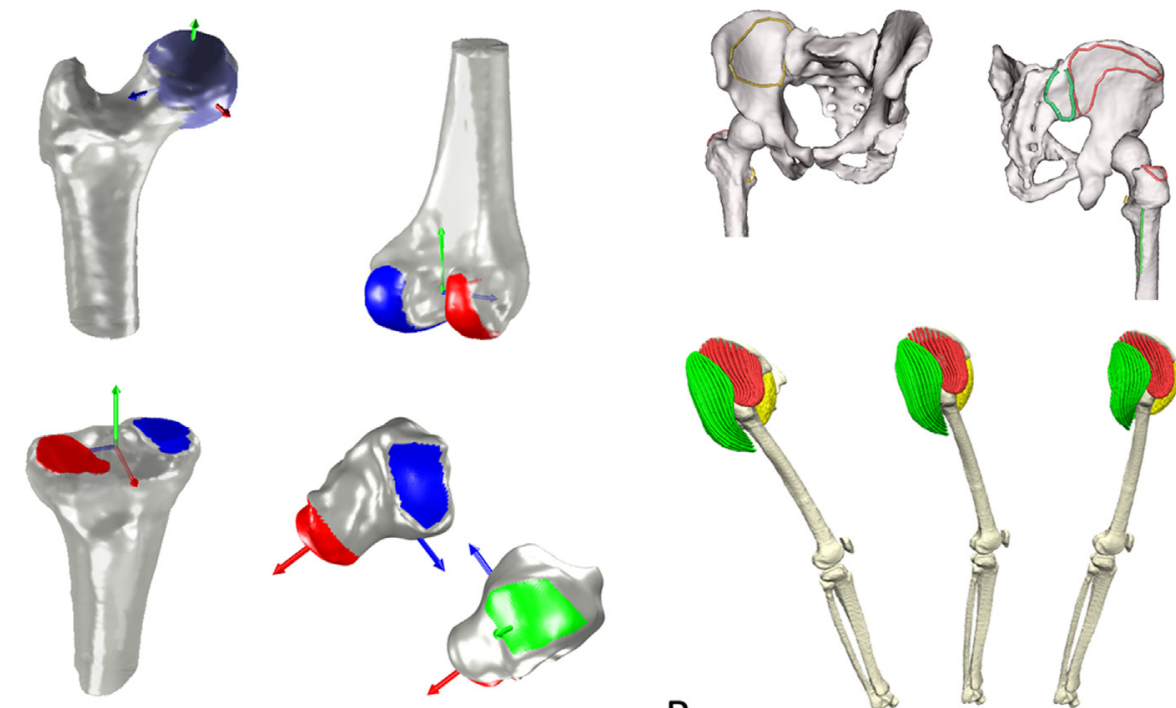

A

B

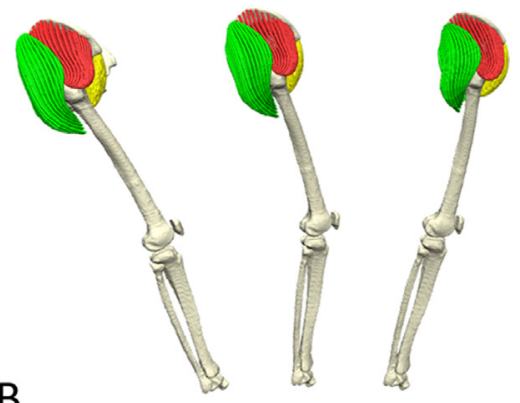

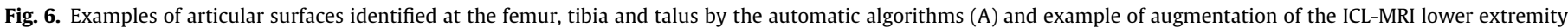
model using an automatically generated subject-specific hip musculature including muscle fibres and attachment areas (B).

musculoskeletal models including musculotendon actuators. This work is framed in a long-term plan aiming to advance the state of the art of anatomical modelling and promote large-scale clinical adoption of personalised computational models of the musculoskeletal system through complete automation of the most challenging modelling tasks.

All data, models and scripts used in this paper are available for download, as detailed in the Appendix.

\section{CRediT authorship contribution statement}

Luca Modenese: Conceptualization, Methodology, Software, Data curation, Validation, Formal analysis, Writing - original draft, Writing - review \& editing. Jean-Baptiste Renault: Investigation, Software, Writing - review \& editing.

\section{Declaration of Competing Interest}

The authors declare that they have no known competing financial interests or personal relationships that could have appeared to influence the work reported in this paper.

\section{Acknowledgements}

LM was supported by an Imperial College Research Fellowship granted by Imperial College London and by an Academy of Medical Sciences Springboard Grant [SBF004\1056] supported by the Academy of Medical Sciences, the British Heart Foundation, Diabetes UK, the Global Challenges Research Fund, the Government Department for Business, Energy and Industrial Strategy and the Wellcome Trust. The authors want to thank Dr Michael Rainbow for making available the MATLAB code employed in the MirandaFemur and Miranda-Tibia algorithms. LM wants to thank Metin Bicer, Arnault Caillet, Bobby Zhang, Clement Favier and Andrew Phillips for the feedback on the manuscript.

\section{Appendix A}

To facilitate the reproducibility and replication of our results, we have released our research code and data with this publication.
All of the data and scripts needed to run the calculations reported in this work, as well as the post-processing scripts to reproduce the figures in the paper are available at https://github.com/modenaxe/ auto-lowerlimb-models-paper and at the project page https:// simtk.org/projects/auto-sk-models. The version of the scripts and data used in this paper are available through Zenodo at https:// zenodo.org/record/4396335. The STAPLE toolbox is openly developed at the repository https://github.com/modenaxe/msk-STAPLE with releases downloadable from the project page https://simtk. org/projects/msk-staple.

\section{Appendix B. Supplementary data}

Supplementary data to this article can be found online at https://doi.org/10.1016/j.jbiomech.2020.110186.

\section{References}

Audenaert, E.A., Van Houcke, J., Almeida, D.F., Paelinck, L., Peiffer, M., Steenackers, G., Vandermeulen, D. 2019. Cascaded statistical shape model based segmentation of the full lower limb in CT. Comput. Methods Biomech. Biomed. Eng. 22, 644-657.

Barber, L., Carty, C., Modenese, L., Walsh, J., Boyd, R., Lichtwark, G., 2017. Medial gastrocnemius and soleus muscle-tendon unit, fascicle, and tendon interaction during walking in children with cerebral palsy. Dev. Med. Child Neurol. 59, 843851.

Barzan, M., Modenese, L., Carty, C.P., Maine, S., Stockton, C.A., Sancisi, N., Lewis, A., Grant, J., Lloyd, D.G., da Luz, S.B., 2019. Development and validation of subjectspecific pediatric multibody knee kinematic models with ligamentous constraints. J. Biomech. 93, 194-203.

Brandon, S.C., Smith, C.R., Thelen, D.G., 2017. Simulation of soft tissue loading from observed movement dynamics. In: Handbook of Human Motion. Springer, pp. $1-34$.

Brito da Luz, S., Modenese, L., Sancisi, N., Mills, P.M., Kennedy, B., Beck, B.R., Lloyd, D. G., 2017. Feasibility of using MRIs to create subject-specific parallel-mechanism joint models. J. Biomech. 53, 45-55.

Carbone, Vincenzo, René Fluit, Pim Pellikaan, Van Der Krogt, M.M.,Janssen, D. Damsgaard, M., Vigneron, L., Feilkas, T., HubertusKoopman, FJM, 2015. TLEM 2.0-A comprehensive musculoskeletal geometry dataset for subject-specific modeling of lower extremity. Journal of biomechanics 48 (5), 734-741.

Cignoni, Paolo, Marco Callieri, Massimiliano Corsini, Matteo Dellepiane, Fabio Ganovelli, Guido Ranzuglia. Meshlab: an open-source mesh processing tool. Eurographics Italian chapter conference, pp. 129-136. 2008. 
Clarke, S., Cobb, J., Jaere, M., Jones, G., Kley, K., Lobenhoffer, P., McCrum, C., Musahl, V., Takeuchi, R., 2018. Osteotomies: Advanced and Complex Techniques. In: ESSKA Instructional Course Lecture Book. Springer, pp. 129-151.

Conconi, M., Leardini, A., Parenti-Castelli, V., 2015. Joint kinematics from functional adaptation: A validation on the tibio-talar articulation. J. Biomech. 48, 29602967.

Damsgaard, M., Rasmussen, J., Christensen, S.T., Surma, E., de Zee, M., 2006. Analysis of musculoskeletal systems in the AnyBody Modeling System. Simul. Model. Pract. Theory 14, 1100-1111.

Davico, G., Pizzolato, C., Killen, B.A., Barzan, M., Suwarganda, E.K., Lloyd, D.G., Carty, C.P., 2019. Best methods and data to reconstruct paediatric lower limb bones for musculoskeletal modelling. Biomech. Modeling Mechanobiol.

Delp, S.L., Anderson, F.C., Arnold, A.S., Loan, P., Habib, A., John, C.T., Guendelman, E., Thelen, D.G., 2007. OpenSim: open-source software to create and analyze dynamic simulations of movement. IEEE Trans. Biomed. Eng. 54, 1940-1950.

Dembia, C.L., Bianco, N.A., Falisse, A., Hicks, J.L., Delp, S.L., 2019. OpenSim Moco: Musculoskeletal optimal control. BioRxiv 839381.

Falisse, A., Pitto, L., Kainz, H., Hoang, H., Wesseling, M., Van Rossom, S., Papageorgiou, E., Bar-On, L., Hallemans, A., Desloovere, K., Molenaers, G., Van Campenhout, A., De Groote, F., Jonkers, I., 2020. Physics-Based Simulations to Predict the Differential Effects of Motor Control and Musculoskeletal Deficits on Gait Dysfunction in Cerebral Palsy: A Retrospective Case Study. Front. Hum. Neurosci. 14.

Falisse, A., Serrancolí, G., Dembia, C.L., Gillis, J., Jonkers, I., De Groote, F., 2019. Rapid predictive simulations with complex musculoskeletal models suggest that diverse healthy and pathological human gaits can emerge from similar control strategies. J. R. Soc. Interface 16, 20190402.

Fischer, M.C.M., Krooß, F., Habor, J., Radermacher, K., 2019. A robust method for automatic identification of landmarks on surface models of the pelvis. Sci. Rep. 9, 13322.

Fox, A.S., Carty, C.P., Modenese, L., Barber, L.A., Lichtwark, G.A., 2018. Simulating the effect of muscle weakness and contracture on neuromuscular control of normal gait in children. Gait \& posture 61, 169-175.

Gonzalez-Ochoa, C., McCammon, S., Peters, J., 1998. Computing moments of objects enclosed by piecewise polynomial surfaces. ACM Trans. Graphics 17, 143-157.

Hamner, S.R., Seth, A., Delp, S.L., 2010. Muscle contributions to propulsion and support during running. J. Biomech. 43, 2709-2716.

Hannah, I., Montefiori, E., Modenese, L., Prinold, J., Viceconti, M., Mazzà, C., 2017. Sensitivity of a juvenile subject-specific musculoskeletal model of the ankle joint to the variability of operator-dependent input. Proc. Inst. Mech. Eng. [H] $231,415-422$.

Henckel, J., Richards, R., Lozhkin, K., Harris, S., Baena, F.R.y., Barrett, A., Cobb, J., 2006. Very low-dose computed tomography for planning and outcome measurement in knee replacement. J. Bone Joint Surgery. British volume 88, 1513-1518.

Hirschmann, A., Buck, F.M., Fucentese, S.F., Pfirrmann, C.W., 2015. Upright CT of the knee: the effect of weight-bearing on joint alignment. Eur. Radiol. 25, 33983404.

Kai, S., Sato, T., Koga, Y., Omori, G., Kobayashi, K., Sakamoto, M., Tanabe, Y., 2014. Automatic construction of an anatomical coordinate system for threedimensional bone models of the lower extremities - Pelvis, femur, and tibia. J. Biomech. 47, 1229-1233.

Kainz, H., Modenese, L., Lloyd, D.G., Maine, S., Walsh, H.P.J., Carty, C.P., 2016. Joint kinematic calculation based on clinical direct kinematic versus inverse kinematic gait models. J. Biomech. 49, 1658-1669.

Marra, M.A., Vanheule, V., Fluit, R., Koopman, B.H., Rasmussen, J., Verdonschot, N., 2015. A Subject-Specific Musculoskeletal Modeling Framework to Predict in Vivo Mechanics of Total Knee Arthroplasty. J. Biomech. Eng. 137, 020904.

Martelli, S., Valente, G., Viceconti, M., Taddei, F., 2015. Sensitivity of a subjectspecific musculoskeletal model to the uncertainties on the joint axes location. Comput. Methods Biomech. Biomed. Eng. 18 (14), 1555-1563.

Matsiushevich, K., Belvedere, C., Leardini, A., Durante, S., 2019. Quantitative comparison of freeware software for bone mesh from DICOM files. J. Biomech. $84,247-251$.

McConville, J.T., Churchill, T.D., Kaleps, I., Clauser, C.E., Cuzzi, J., 1980. Anthropometric Relationships of Body and Body Segment Moments of Inertia, Tech. Rep. AFAMRL-TR-80-119. Aerospace Medical Research Laboratory, Wright-Patterson Air Force Base, Dayton, $\mathrm{OH}$.

Miranda, D.L., Rainbow, M.J., Leventhal, E.L., Crisco, J.J., Fleming, B.C., 2010. Automatic determination of anatomical coordinate systems for threedimensional bone models of the isolated human knee. J. Biomech. 43, 16231626.

Mirtich, B., 1996. Fast and Accurate Computation of Polyhedral Mass Properties. Journal of Graphics Tools 1, 31-50.

Modenese, L., Caillet, A., Favier, C., Phillips, A., Kohout, J., 2020. Simulation of the hip muscles kinematics during gait using highly discretised anatomical models https://doi.org/10.5281/zenodo.4396076.

Modenese, L., Ceseracciu, E., Reggiani, M., Lloyd, D.G., 2016. Estimation of musculotendon parameters for scaled and subject specific musculoskeletal models using an optimization technique. J. Biomech. 49, 141-148.

Modenese, L., Jaere, M., Jones, G.G., Phillips, A., McGregor, A.H., Cobb, J.P., 2019. Integration of external knee joint loads in the pre-surgical planning of high tibial osteotomy: a proof-of-concept study XXVII Congress of the International Society of Biomechanics (ISB2019) and 43rd Annual Meeting of the American Society of Biomechanics (ASB2019), Calgary, Canada. Abstract available at https://doi.org/10.5281/zenodo.4396054.
Modenese, L., Kohout, J., 2020. Automated Generation of Three-Dimensional Complex Muscle Geometries for Use in Personalised Musculoskeletal Models. Ann. Biomed. Eng. 48, 1793-1804.

Modenese, L., Montefiori, E., Wang, A., Wesarg, S., Viceconti, M., Mazzà, C., 2018. Investigation of the dependence of joint contact forces on musculotendon parameters using a codified workflow for image-based modelling. J. Biomech. 73, 108-118.

Montefiori, E., Modenese, L., Di Marco, R., Magni-Manzoni, S., Malattia, C., Petrarca, M., Ronchetti, A., de Horatio, L.T., van Dijkhuizen, P., Wang, A., 2019a. An imagebased kinematic model of the tibiotalar and subtalar joints and its application to gait analysis in children with Juvenile Idiopathic Arthritis. J. Biomech. 85, 2736.

Montefiori, E., Modenese, L., Di Marco, R., Magni-Manzoni, S., Malattia, C., Petrarca, M., Ronchetti, A., De Horatio, L.T., van Dijkhuizen, P., Wang, A., 2019b. Linking Joint Impairment and Gait Biomechanics in Patients with Juvenile Idiopathic Arthritis. Ann. Biomed. Eng. 47, 2155-2167.

Nardini, F., Belvedere, C., Sancisi, N., Conconi, M., Leardini, A., Durante, S., ParentiCastelli, V., 2020. An Anatomical-Based Subject-Specific Model of In-Vivo Knee Joint 3D Kinematics From Medical Imaging. Appl. Sci. 10, 2100.

Noguchi, S., Nishio, M., Yakami, M., Nakagomi, K., Togashi, K., 2020. Bone segmentation on whole-body CT using convolutional neural network with novel data augmentation techniques. Comput. Biol. Med. 121, 103767.

Nolte, D., Ko, S.-T., Bull, A.M.J., Kedgley, A.E., 2020. Reconstruction of the lower limb bones from digitised anatomical landmarks using statistical shape modelling. Gait \& Posture 77, 269-275.

Nolte, D., Tsang, C.K., Zhang, K.Y., Ding, Z., Kedgley, A.E., Bull, A.M.J., 2016. Nonlinear scaling of a musculoskeletal model of the lower limb using statistical shape models. J. Biomech. 49, 3576-3581.

Pataky, Todd, 2012. One-dimensional statistical parametric mapping in Python. Computer Methods in Biomechanics and Biomedical Engineering 15, 295301.

Pitto, L., Kainz, H., Falisse, A., Wesseling, M., Van Rossom, S., Hoang, H., Papageorgiou, E., Hallemans, A., Desloovere, K., Molenaers, G., Van Campenhout, A., De Groote, F., Jonkers, I., 2019. SimCP: A Simulation Platform to Predict Gait Performance Following Orthopedic Intervention in Children With Cerebral Palsy. Front. Neurorobotics 13.

Rainbow, M.J., Miranda, D.L., Cheung, R.T.H., Schwartz, J.B., Crisco, J.J., Davis, I.S., Fleming, B.C., 2013. Automatic determination of an anatomical coordinate system for a three-dimensional model of the human patella. J. Biomech. 46, 2093-2096.

Renault, J.-B., Aüllo-Rasser, G., Donnez, M., Parratte, S., Chabrand, P., 2018. Articularsurface-based automatic anatomical coordinate systems for the knee bones. J. Biomech. 80, 171-178.

Sancisi, N., Parenti-Castelli, V., 2011. A new kinematic model of the passive motion of the knee inclusive of the patella. J. Mech. Robotics 3, 041003.

Saxby, D.J., Modenese, L., Bryant, A.L., Gerus, P., Killen, B., Fortin, K., Wrigley, T.V., Bennell, K.L., Cicuttini, F.M., Lloyd, D.G., 2016. Tibiofemoral contact forces during walking, running and sidestepping. Gait \& Posture 49, 78-85.

Scheys, L., Jonkers, I., Loeckx, D., Spaepen, A., Suetens, P., 2006. Automatic identification of muscle insertion sites in MR images using atlas-based, nonrigid registration. Gait \& Posture 24. Supplement 2, S71-S72.

Seth, A., Hicks, J.L., Uchida, T.K., Habib, A., Dembia, C.L., Dunne, J.J., Ong, C.F., DeMers, M.S., Rajagopal, A., Millard, M., Hamner, S.R., Arnold, E.M., Yong, J.R., Lakshmikanth, S.K., Sherman, M.A., Ku, J.P., Delp, S.L., 2018. OpenSim: Simulating musculoskeletal dynamics and neuromuscular control to study human and animal movement. PLoS Comput. Biol. 14, e1006223.

Sholukha, V., Chapman, T., Salvia, P., Moiseev, F., Euran, F., Rooze, M., Jan, S.V.S., 2011. Femur shape prediction by multiple regression based on quadric surface fitting. J. Biomech. 44, 712-718.

Steger, S., Kirschner, M., Wesarg, S., 2012. Articulated atlas for segmentation of the skeleton from head \& neck CT datasets. In 9th IEEE International Symposium on Biomedical Imaging (ISBI). Barcelona, Spain.

Suwarganda, E.K., Diamond, L.E., Lloyd, D.G., Besier, T.F., Zhang, J., Killen, B.A., Savage, T.N., Saxby, D.J., 2019. Minimal medical imaging can accurately reconstruct geometric bone models for musculoskeletal models. PLoS ONE 14 e0205628.

Taddei, F., Martelli, S., Valente, G., Leardini, A., Benedetti, M.G., Manfrini, M., Viceconti, M., 2012. Femoral loads during gait in a patient with massive skeletal reconstruction. Clin. Biomech. 27, 273-280.

Valente, G., Crimi, G., Vanella, N., Schileo, E., Taddei, F., 2017a. nmsBuilder: Freeware to create subject-specific musculoskeletal models for OpenSim. Comput. Methods Programs Biomed. 152, 85-92.

Valente, G., Pitto, L., Schileo, E., Piroddi, S., Leardini, A., Manfrini, M., Taddei, F., 2017b. Relationship between bone adaptation and in-vivo mechanical stimulus in biological reconstructions after bone tumor: A biomechanical modeling analysis. Clin. Biomech. 42, 99-107.

Valente, G., Pitto, L., Testi, D., Seth, A., Delp, S.L., Stagni, R., Viceconti, M., Taddei, F., 2014. Are Subject-Specific Musculoskeletal Models Robust to the Uncertainties in Parameter Identification?. PLoS ONE 9, e112625.

Viceconti, Marco, Gordon Clapworthy, Serge Van Sint, Jan, 2008. The Virtual Physiological Human-A European Initiative for In Silico Human Modelling-. The journal of physiological sciences.

Victor, J., Premanathan, A., 2013. Virtual 3D planning and patient specific surgical guides for osteotomies around the knee: a feasibility and proof-of-concept study. Bone Joint J. 95, 153-158. 
Wesseling, M., de Groote, F., Jonkers, I., 2014. The effect of perturbing body segment parameters on calculated joint moments and muscle forces during gait. J. Biomech. 47, 596-601.

Winter, D.A., 2009. Biomechanics and motor control of the human movement. John Wiley \& Sons, Waterloo, Ontario, Canada.

Yin, L., Chen, K., Guo, L., Cheng, L., Wang, F., Yang, L., 2015. Identifying the Functional Flexion-extension Axis of the Knee: An In-Vivo Kinematics Study. PLoS ONE 10, e0128877.
Yushkevich, P.A., Piven, J., Hazlett, H.C., Smith, R.G., Ho, S., Gee, J.C., Gerig, G., 2006. User-guided 3D active contour segmentation of anatomical structures: significantly improved efficiency and reliability. Neuroimage 31, 1116-1128.

Zhang, J., Fernandez, J., Hislop-Jambrich, J., Besier, T.F., 2016. Lower limb estimation from sparse landmarks using an articulated shape model. J. Biomech. 49, 3875 3881 